\section{Investigating Undergraduate Students' Use of Intuitive Reasoning and Evolutionary Knowledge in Explanations of Antibiotic Resistance}

\author{
Melissa Richard, ${ }^{\dagger}$ John D. Coley, ${ }^{\ddagger}$ and Kimberly D. Tanner ${ }^{\dagger *}$ \\ 'SEPAL: The Science Education Partnership and Assessment Laboratory, Department of Biology, \\ San Francisco State University, San Francisco, CA 94132; ₹CORE: Conceptual Organization, \\ Reasoning and Education Laboratory, Department of Psychology, Northeastern University, \\ Boston, MA 02115
}

\begin{abstract}
Natural selection is a central concept throughout biology; however, it is a process frequently misunderstood. Bacterial resistance to antibiotic medications provides a contextual example of the relevance of evolutionary theory and is also commonly misunderstood. While research has shed light on student misconceptions of natural selection, minimal study has focused on misconceptions of antibiotic resistance. Additionally, research has focused on the degree to which misconceptions may be based in the complexity of biological information or in pedagogical choices, rather than in deep-seated cognitive patterns. Cognitive psychology research has established that humans develop early intuitive assumptions to make sense of the world. In this study, we used a written assessment tool to investigate undergraduate students' misconceptions of antibiotic resistance, use of intuitive reasoning, and application of evolutionary knowledge to antibiotic resistance. We found a majority of students produced and agreed with misconceptions, and intuitive reasoning was present in nearly all students' written explanations. Acceptance of a misconception was significantly associated with production of a hypothesized form of intuitive thinking (all $p$ $\leq \mathbf{0 . 0 5}$ ). Intuitive reasoning may represent a subtle but innately appealing linguistic shorthand, and instructor awareness of intuitive reasoning's relation to student misunderstandings has potential for addressing persistent misconceptions.
\end{abstract}

\section{INTRODUCTION}

Natural selection is a primary driving force of evolution, the central and unifying mechanism throughout biology. However, accurate understanding of natural selection has been found to be as low as $2 \%$ in studies of populations of entering biology majors, and even a study of biology graduate students found that fewer than $30 \%$ of those surveyed could provide accurate explanations for the process of adaptation (Gregory and Ellis, 2007; Gregory, 2009). There is an underlying expectation that university students emerge as rising experts in their field, but natural selection remains poorly understood among students at all educational levels.

Antibiotic resistance offers a commonplace and relevant contextualization of the principle of natural selection, as it is a growing issue in the United States and worldwide. As illness-inducing bacteria are exposed to an antibiotic medication, bacteria that are susceptible to the medicine are killed off. However, due to variations in genetic composition of individual bacteria, not every bacterium will be killed; those that survive can continue to reproduce and potentially cause repeated illness. Resulting populations of bacteria may no longer be affected by the previous medication, necessitating careful prescription and use of antibiotics. Studies into the causes of antibiotic resistance have identified both patient habits and inappropriate prescription by medical
Hannah Sevian, Monitoring Editor

Submitted November 10, 2016; Revised May 25 2017; Accepted June 5, 2017

CBE Life Sci Educ September 1, 2017 16:ar55 DOI:10.1187/cbe.16-11-0317

*Address correspondence to: Kimberly D. Tanner (kdtanner@asfsu.edu).

(c) 2017 M. Richard et al. CBE-Life Sciences Education @ 2017 The American Society for Cell Biology. This article is distributed by The American Society for Cell Biology under license from the author(s). It is available to the public under an Attribution-Noncommercial-Share Alike 3.0 Unported Creative Commons License (http:// creativecommons.org/licenses/by-nc-sa/3.0) "ASCB $®$ " and "The American Society for Cell Biology $\circledR^{\prime}$ are registered trademarks of The American Society for Cell Biology. 
professionals as factors in misuse of antibiotics (Belongia et al., 2002; Wester et al., 2002; Eng et al., 2003; McNulty et al., 2007). These findings indicate that a cogent understanding of the nature and function of antibiotics is lacking in both the general public and those who have completed extensive biology education.

While research has explored instructional strategies to improve knowledge of natural selection, growing evidence suggests that challenges in evolutionary understanding may be rooted in deeply held intuitive frameworks rather than in the complexity of biological concepts themselves (Shtulman and Schulz, 2008; Coley and Tanner, 2012). Extensive cognitive science research has demonstrated that humans intuitively reason about biological entities and phenomena in predictable patterns (Carey, 1985; Inagaki and Hatano, 2002, 2006; Atran and Medin, 2008). Additionally, sociocultural approaches to science learning research have established that individuals develop a variety of "conceptual profiles," or models of conceptualizing their understanding of the world, based on their own experiences (Sepulveda et al., 2014). The ways in which these patterns of thinking relate to biological misconceptions is an ongoing area of research. Three forms of intuitive reasoning have been identified, in particular, as potentially linked to biological misconceptions; these include teleological, essentialist, and anthropocentric reasoning (Coley and Tanner, 2012, 2015).

Intuitive explanations for biological phenomena related to these three forms of reasoning have traditionally been studied in children, and these intuitive reasoning patterns are far less studied in older students and adults. However, the presence of intuitive reasoning has increasingly been observed to persist well beyond childhood into high school, undergraduate education, and beyond (Kelemen, 2011; Shtulman and Valcarcel, 2012). Adults and professional scientists may maintain intuitive reasoning frameworks, and while scientific education can allow accurate explanations to outweigh intuitive ones, intuitive reasoning itself is deeply rooted and persistent (Kelemen and Rosset, 2009; Shtulman and Valcarcel, 2012; Shtulman and Harrington, 2015). The persistence of this reasoning raises questions about the implications of intuitive frameworks for understanding biology. It is still not known how accurate scientific frameworks transition to, build upon, or interact with intuitive understandings, and students' "misconceptions" can offer valuable insight into how instruction can build more complete understandings of scientific phenomena beyond simply focusing on correcting inaccurate ideas (Maskiewicz and Lineback, 2013; Crowther and Price, 2014; Evans, 2017). Intuitive patterns of informal assumptions or predispositions are developed at an early age and can be useful in trying to understand the world around us (Evans et al., 2012). However, intuitive reasoning can lead to inappropriate conclusions when applied in scientific contexts. These contexts are only beginning to be fully investigated; here, we explore how intuitive reasoning may relate specifically to misconceptions of antibiotic resistance. We describe here the three forms of intuitive reasoning and their relevance for biology misconceptions.

Teleological thinking is a causal form of intuitive reasoning that assumes an implicit purpose and attributes a goal or need as a contributing agent for a change or event. Teleological reasoning is particularly common in student misconceptions of evolutionary mechanisms and has been observed to persist well into adulthood (Gregory, 2009). Attributing the existence of traits or the process of evolutionary change primarily to "needs" clashes with acknowledgment of underlying mechanisms that are based in individual genetic variation and inheritance. Statements such as "finches diversified in order to survive" and "fungi grow in forests to help with decomposition" are appealing explanations for those with basic scientific understanding (Kelemen and Rosset, 2009). However, persistence of this reasoning is evident in the often imprecise explanations by even those with more extensive scientific expertise. This passage from a website by the National Institute of Health provides one example:

As microbes evolve, they adapt to their environment. If something stops them from growing and spreading-such as an antimicrobial - they evolve new mechanisms to resist the antimicrobials by changing their genetic structure.

Descriptions like this are common across various sources of purported scientific authority (Gregory, 2009). Despite the perhaps surface-level cogency of this explanation, a consideration of the underlying mechanisms of natural selection reveals the inaccuracies it implicitly presents: phenotypical change is neither intentional to fit an environment nor driven by an individual's intentional effort to alter its genetics. Rather, adaptations reflect incidental successes of pre-existing alternate genotypes. While more precise explanations make underlying mechanisms more explicit, teleological explanations remain "seductive" both for scientific experts and novices alike (Sealey and Oakley, 2014).

Essentialist reasoning is the tendency to assume that members of a categorical group are relatively uniform and static due to a core underlying property or "essence" that unites them (Shtulman, 2006). This type of thinking can cognitively reduce the complexity of information and has likely been adaptive for humans, but it disregards the importance and role of variability in natural selection. Misconceptions rooted in essentialist reasoning often allude to a "transformational" theory of evolution in which a population, as a unit, gradually transforms, for example, "The moths gradually became darker over time." This conceptual framework of evolutionary change is in contrast to a variational view, in which selection is understood to act on differences in individuals within a population rather than at the population or species level, for example, "Darker moths were more likely to reproduce than lighter moths and after generations, the population contained more individual moths that were dark-colored." Shtulman and Schulz (2008) suggest that, while essentialism often underlies creationist denials of evolution on the basis that a species' essence is immutable, essentialist reasoning also contributes to a lack of understanding of evolution even for those who accept evolution on a cognitive level. Even students who understand that species can change over time may mistakenly believe that selection gradually acts on the "essence" of an entire species rather than recognizing that populations (and species) change as a result of selection acting on individual members of a species. In regard to evolution, grasping the importance of variability across members of a group has been found to be one of the most 
challenging aspects of understanding natural selection (Speth et al., 2014).

Anthropocentric reasoning describes a form of reasoning by analogy to humans, often either by inappropriately attributing predominant biological importance to humans relative to other organisms or by anthropomorphizing organisms or processes by projecting human qualities or behaviors onto them. Common manifestations of anthropocentric thinking in biology misconceptions might include "Until recently, species rarely went extinct: humans have caused the majority of extinctions" or "Plants want to bend toward the light." These types of statements, while appearing very different in content, share a common root in their exaggeration of human importance and human traits in the natural world. The misattribution of human influence can lead to both 1) the tendency to see humans as biologically discontinuous with the rest of the animal world (anthropocentrize), particularly in Western industrialized societies, and 2) the tendency to personify (anthropomorphize) nonhuman animals and reason about other organisms by analogy to humans (Coley and Tanner, 2015).

\section{Relations between Intuitive Reasoning and Misconceptions}

Previous work has begun to investigate and identify potential relationships between intuitive reasoning and systems of misconceptions. Coley and Tanner (2015) found significant associations between specific forms of intuitive reasoning and biological misconceptions. When these results were disaggregated, stronger associations were seen among entering biology students relative to non-biology majors. Based on this finding, it was hypothesized that formal biology education may somehow reify the intuitive reasoning behind common biology misconceptions. However, the degree to which these previous results can be expanded to other populations of students, other misconceptions, and other contexts is unclear.

Our study examines how intuitive reasoning relates to misconceptions of a single topic-antibiotic resistance-rather than examining many disparate misconceptions across a variety of conceptual contexts. Here, we further explore the potential relationships between intuitive reasoning and misconceptions among advanced biology majors (ABM) and in entering biology majors (EBM), non-biology majors (NBM), and biology faculty (BF). We address four research questions: 1) To what extent do undergraduate students with various levels of formal biology education embrace misconceptions of antibiotic resistance, a contextualized example of natural selection? 2) To what extent do students evidence intuitive reasoning in their written explanations? 3) What relationships exist between acceptance of misconceptions and the use of intuitive reasoning, and are those relations the same for various student groups and faculty? 4) To what extent do various populations evidence an application of evolutionary knowledge in their reasoning on antibiotic resistance?

\section{METHODS}

This study aimed to understand conceptualizations of antibiotic resistance among groups of undergraduate students with various levels of biology education. A novel written assessment tool was developed to evaluate the participant populations in the following areas: agreement with misconceptions of antibiotic resistance, use of intuitive thinking in reasoning about antibiotic resistance, and relationships between acceptance of misconceptions and application of intuitive reasoning. The assessment was also developed with a goal of investigating the application of knowledge of natural selection to reasoning about antibiotic resistance. Here, we describe briefly the recruitment of the participant populations, development of the assessment tool, implementation of the assessment, and the analytical methods used to categorize and compare participant responses.

\section{Recruitment and Participant Populations}

Four participant populations were included in this study (Table 1), all recruited from the students and faculty of a large, urban university. To recruit student populations, we contacted course instructors and obtained signed permission for the main researcher to assess students within the instructors' courses, as required by the institutional review board at the researchers' home institution (protocol number: E15-123, approved April 10, 2015; modified November 6, 2015). All student populations participated in completing the assessment as a classroom activity for the day but were given the opportunity to opt out of including their responses in the study.

Faculty participants were included to obtain an expert-level data set to compare with student populations. We identified BF who had primary research focused on microbiology, genetics, or evolution and contacted them via email to request their participation. Faculty on sabbatical and faculty directly involved in the courses from which students were recruited were excluded from recruitment.

\section{Assessment Tool Development}

Given the lack of an existing instrument to address our research questions, we developed a novel written assessment tool to investigate undergraduate students' understanding of antibiotic resistance (see Box 1). Details on the development of the assessment tool can be found in the Supplemental Material.

\section{Assessment Implementation}

Participants were informed that the assessment addressed antibiotic resistance and that the activity was not a test or assignment with any impact on the course grade. All participants gave

TABLE 1. Participant populations

\begin{tabular}{lccccc}
\hline Participant group & Number invited & Sample size & Participation rate & Participants of color & Female participants \\
\hline NBM & 58 & 58 & $100 \%$ & $59 \%$ & $55 \%$ \\
EBM & 320 & 319 & $99.7 \%$ & $85 \%$ & $65 \%$ \\
ABM & 107 & 107 & $100 \%$ & $74 \%$ & $62 \%$ \\
BF & 28 & 14 & $50 \%$ & $43 \% * *$ & $50 \%$ \\
\hline
\end{tabular}

$* * p=0.0092$ (Pearson chi-square). 


\section{BOX 1. Assessment Tool.}

1. "How would you explain antibiotic resistance to a fellow student in this class/to a professional colleague?"

Instructions on pages $\mathbf{2 - 5}$

"Please read the statement below and circle a response on the scale:

Strongly Disagree, Disagree, Agree, Strongly Agree"

2. "Individual bacteria develop mutations in order to become resistant to an antibiotic and survive."

Hypothesized teleological statement

3. "Individual bacteria are genetically similar and equally likely to be killed by an antibiotic."

Hypothesized essentialist statement

4. "Bacteria develop resistance to antibiotics because of changes within humans."

Hypothesized anthropocentric statement

5. "Antibiotic resistance is an example of evolution."

In the space below, please explain with as much detail as possible.

informed consent for human subjects research (protocol number: E15-123). The main researcher guided participants through the assessment one item at a time, and students were given 5 minutes to complete each item before the next item was distributed. Faculty participants were given the assessment using a similar protocol in one-on-one meetings.

\section{Analyses of Participant Responses to Assessment Items}

We give here our analytic methodologies grouped by open- and closed-ended assessment prompts and our methods for relating intuitive reasoning with misconceptions.

Analysis of Written Reasoning in Open-Ended Prompts. We analyzed student misconceptions through coding of written responses to the open-ended assessment items. The presence of scientifically inaccurate information evidencing a misconception was coded and quantified within each population. We also coded students' explanations for the presence of teleological, essentialist, and anthropocentric thinking. To do so, the main researcher created a rubric of indicative criteria for each concept based on the literature and from coding a subset of responses to each prompt. This rubric was applied to remaining responses, and the process was repeated as new criteria emerged. Once coding had been completed, the researchers conducted an interrater reliability analysis. The main researchers independently coded a random sample of $10 \%$ of the total data set, blinded to population type, for each prompt for comparative analysis. All qualitative coding reached $80 \%$ or greater consensus between trained coders.

To investigate the application of evolutionary knowledge to the topic of antibiotic resistance, we coded participants' explanations of antibiotic resistance (unframed assessment item 1) for evidence of knowledge of natural selection. For our purposes, this was defined as a response referencing individual variability within a population and the idea that individual differences contribute to differential survival. Coding for evidence of natural selection knowledge was not mutually exclusive with other codes, and participants discussing selection could also evidence misconceptions or intuitive reasoning.
Analysis of Agreement with Statements in Closed-Ended Prompts. We examined students' agreement or disagreement with the misconceptions statements as indicated by their responses to a four-point Likert scale. We analyzed this in terms of categorical agreement, wherein agreement was made a binary categorical variable. To categorize these responses, we classified each student as either "agreeing" (i.e., giving a rating of 3 or 4) or "disagreeing" (giving a rating of 1 or 2) with each individual misconception statement and compared the number of NBM, EBM, ABM, and BF who agreed with each misconception statement. To look at differences between participant populations in agreement with individual misconception statements, we conducted $2 \times 2$ Pearson's chi-square tests separately between populations. All statistical comparisons were generated using JMP, version 12 (2015; SAS Institute, Cary, NC).

Analyses of Relations between Intuitive Reasoning and Agreement with Misconceptions. For each misconception statement, we classified participants based on 1) whether they agreed or disagreed with the statement (as an indication of whether they held the misconception), and 2) whether the form of intuitive reasoning we hypothesized to be associated with that misconception was present in their written explanations or not. We then conducted $2 \times 2$ Pearson's chi-square analyses within each participant population on the relative proportions of participants indicating agreement and participants with intuitive reasoning in their written response to examine nonrandom presence of the same type of intuitive thinking in both the open-ended (coded) question and the closed-ended misconception prompt. For unframed assessment item 1, we examined relationships between participants' production of any misconceptions in their explanations of antibiotic resistance and their production of any form of intuitive reasoning within their responses.

\section{RESULTS}

We give here the results of data analyses presented by individual assessment items in the order in which participants responded (see Box 1). These include analyses of the first unframed assessment item, three framed assessment items consisting of misconception statements hypothesized to represent each hypothesized form of intuitive reasoning, and an assessment item included to elicit application of prior evolutionary knowledge to the topic of antibiotic resistance. Analyses of participant responses to assessment items are organized, where applicable, by research questions raised previously: 1) To what extent do participants embrace misconceptions of antibiotic resistance? 2) To what extent do participants evidence intuitive reasoning in their written explanations? 3) What correlations exist between acceptance of misconceptions and the use of intuitive reasoning? 4) To what extent do participants evidence an application of evolutionary knowledge in their reasoning on antibiotic resistance?

\section{Participant Populations}

This study included data from a total of 498 participants (Table 1). All analyses and comparisons described below are based on these undergraduate students $(n=484)$ and BF $(n=14)$. Participants whose responses did not address the prompt were excluded from analysis. 


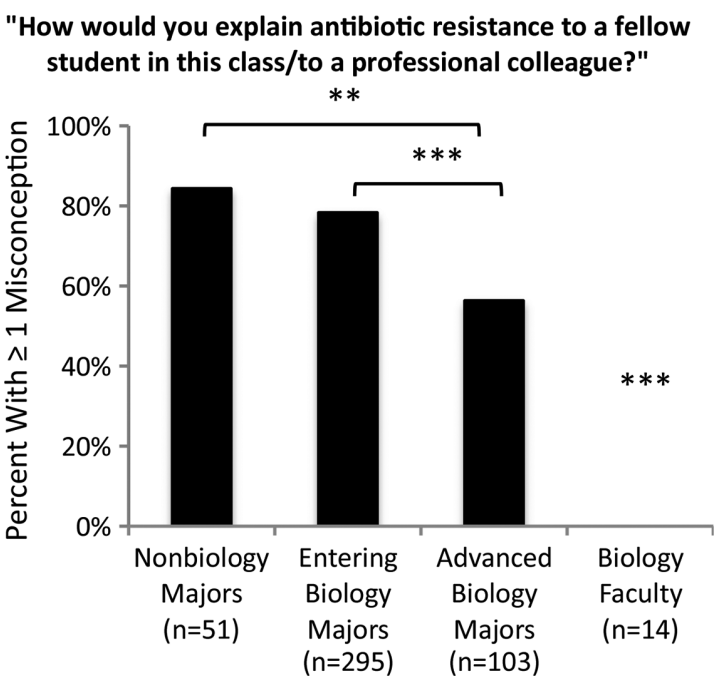

FIGURE 1. Misconception production in response to unframed assessment item 1: "How would you explain antibiotic resistance to a fellow student in this class/to a professional colleague?" $* * *, p<0.001$; between BF and all student populations; **, $p<0.01$ between ABM and NBM. No significant difference between NBM and EBM populations.

Assessment Item 1. Unframed: "How would you describe antibiotic resistance to a fellow student in this class?"

To investigate participants' production of novel misconceptions and intuitive reasoning without specific prompting, our first assessment item asked for a written explanation of antibiotic resistance. We give here the analyses of each of these measures in response to the unframed assessment item.

Misconceptions Produced in Unframed Participant Explanations of Antibiotic Resistance. In response to the unframed assessment item, 73\% of all students produced scientifically inaccurate information in their initial explanations (Figure 1). EBM were significantly more likely to produce misconceptions than were advanced majors $\left(\chi^{2}=18.571, N=\right.$ $398, p<0.0001)$. BF produced no scientifically inaccurate information and were significantly different from all student populations (all $p<0.0001$ ). Examples of student misconceptions produced in response to assessment item 1 are shown in Table 2.

Intuitive Reasoning Produced in Unframed Participant Explanations of Antibiotic Resistance. In response to the unframed assessment item, more than $60 \%$ of all students produced some form of intuitive reasoning in their written explanations (Figure 2A). BF produced significantly less intuitive reasoning on assessment item 1, differing from all student populations (all $p<0.0001$ ). ABM also produced significantly less intuitive reasoning than EBM $\left(\chi^{2}=4.896\right.$, $N=398, p<0.05)$. The types of intuitive reasoning produced varied greatly; however, the proportions they were produced in were consistent across student populations (Figure 2B). Anthropocentric reasoning was the most commonly produced form of intuitive reasoning and was present in approximately half of all student populations. Teleological reasoning was the least common and was present in only a small percentage of all populations, including faculty.

TABLE 2. Misconceptions of antibiotic resistance produced by participants in response to the question "How would you explain antibiotic resistance to a fellow student in this class?"

\begin{tabular}{|c|c|c|}
\hline$\underline{\text { Participant group }}$ & Sample evidence & Percent of participant group ( $n$ ) \\
\hline $\operatorname{NBM}(n=51)$ & $\begin{array}{l}\text { "Antibiotic resistance is nothing but a modified version of a certain virus that is going to } \\
\text { act like a defense mechanism to fight off the virus." } \\
\text { "Antibiotic resistance is a choice people make to refrain from medicine and seek healing } \\
\text { from other sources." } \\
\text { "It's the biological mechanism inside the body that helps prevent all outside invaders } \\
\text { such as bacteria that attack our body." } \\
\text { "Antibiotic resistance occurs when an organism is not able to produce the antibodies to } \\
\text { fight diseases, infection, etc." }\end{array}$ & $84(43)$ \\
\hline $\operatorname{EBM}(n=295)$ & $\begin{array}{l}\text { "Antibiotic resistance is when certain viruses will not be stopped by the antibodies } \\
\text { produced by the human body." } \\
\text { "The antibiotic resists all other possibilities of further bacteria contaminating the } \\
\text { organism. In other words, a bacteria is put into the organism to fight OFF bacteria." } \\
\text { "Antibiotics are a dead form or inactive bacterial cell." } \\
\text { "Antibiotic resistance is something within or outside a living organism that repels or } \\
\text { resists the help of antibiotics. You would only use antibiotic resistance if [the } \\
\text { antibiotic] proves to be too strong for a host." }\end{array}$ & $78(231)$ \\
\hline $\mathrm{ABM}(n=103)$ & $\begin{array}{l}\text { "Your body has resistance and won't absorb antibiotics to fight against bacteria or virus } \\
\text { in your body." } \\
\text { "When you have antibiotic resistance the antibodies will not work because they are } \\
\text { resistant to the bacteria." } \\
\text { "It's like how you get chicken pox once you can't get it again because you develop } \\
\text { resistance to that one strain of bacteria." } \\
\text { "As a drug is taken, the body recognizes the drug and slowly builds tolerance. Some of } \\
\text { the cells are tolerant and over time resistant cells become a majority." }\end{array}$ & $56(58)$ \\
\hline $\mathrm{BF}(n=14)$ & $\mathrm{N} / \mathrm{A}$ & $0(0)$ \\
\hline
\end{tabular}


“How would you explain antibiotic resistance to a fellow student in this class/to a professional colleague?"

A)

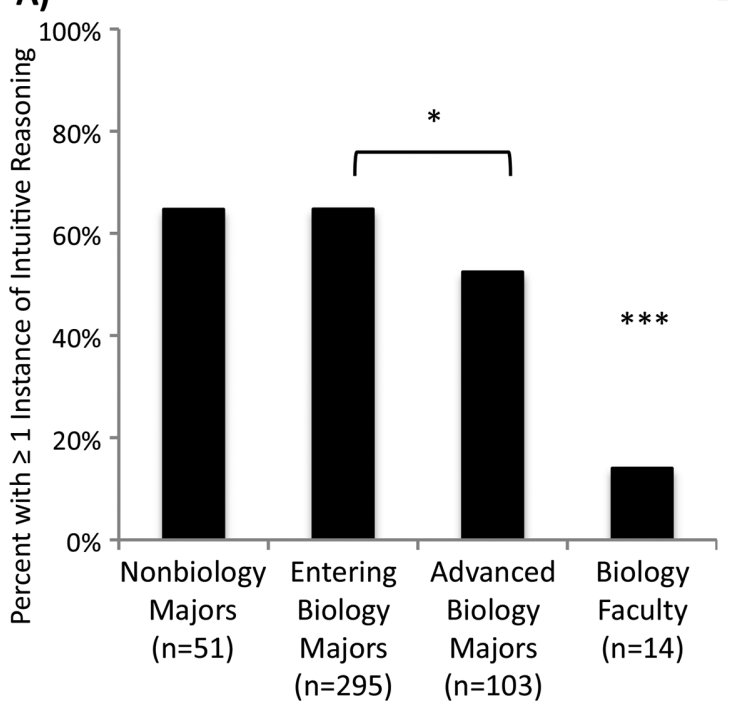

B)

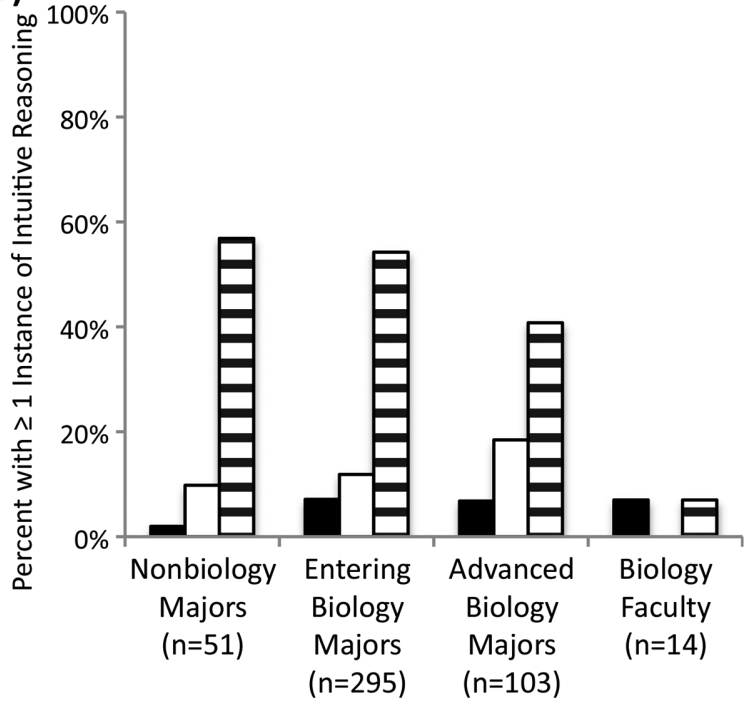

FIGURE 2. Intuitive reasoning production in total and disaggregated by type in response to unframed assessment item 1: "How would you explain antibiotic resistance to a fellow student in this class/to a professional colleague?" (A) Cumulative presence of any instance of intuitive reasoning (teleology, essentialism, anthropocentricism). ${ }^{* *}, p<0.0001$ between $\mathrm{BF}$ and all student populations; ${ }^{*}, p<0.05$ between ABM and EBM populations. (B) Disaggregated presence of each form of intuitive reasoning found in each participant population. Teleology (black bars), essentialism (white bars), anthropocentricism (horizontal striped bars).

Representative quotes of student data evidencing intuitive reasoning are shown in Table 3 .

Associations Between Misconceptions and Intuitive Reasoning in Unframed Assessment Item. If misconceptions stem from underlying intuitive reasoning, students who posit scientifically inaccurate ideas should be more likely to also evidence intuitive reasoning in their writing. For all student populations, a significant relation was seen between production of a misconception and evidence of intuitive reasoning (all $p<0.0001$; Figure 3). While faculty evidenced intuitive reasoning at low levels, they did not produce inaccurate statements and thus showed no associations between intuitive reasoning and misconceptions.

\section{Assessment Items 2-4: Intuitive Reasoning-Framed Misconception Statements}

To investigate the extent to which students would embrace misconceptions we hypothesized to be rooted in intuitive reasoning, we presented participants with three misconception statements. Using a Likert scale, participants agreed or disagreed and explained their reasoning (Box 1). Statistical measures of each population's agreement with a misconception statement are detailed below by misconception.

Agreement with Misconceptions. In response to our misconception statements, more than $94 \%$ of all students agreed with at least one statement (Figure 4A). ABM differed significantly from EBM $\left(\chi^{2}=12.045, N=426, p=0.013\right)$, and BF were significantly less likely to agree with misconception statements compared with all student groups (all $p<0.0001$ ). Agreement with individual misconception statements varied in the degree to which students accepted them; response to each statement is detailed below.
Assessment Item 2. Hypothesized Teleological Misconception Statement: "Individual bacteria develop mutations in order to become resistant to an antibiotic and survive." A majority of students (81\%) in all populations agreed with the misconception statement we hypothesized to be rooted in teleology (Figure 4B). While $84 \%$ and $85 \%$ of NBM and EBM agreed, respectively, $74 \%$ of $\mathrm{ABM}$ agreed, differing significantly from entering majors $\left(\chi^{2}=7.222, N=426, p=0.0072\right)$. BF significantly differed from all student populations.

Assessment Item 3. Hypothesized Essentialist Misconception Statement: "Individual bacteria are genetically similar and equally likely to be killed off by an antibiotic medication." Agreement with the essentialist statement was relatively low (Figure 4C). Among students, 37\% accepted the essentialist misconception (36\% of NBM; $38 \%$ of EBM; $36 \%$ of ABM), and no significant differences were seen among student populations. While $7 \%$ of $\mathrm{BF}$ indicated agreement, this difference between students and faculty was not significant.

Assessment Item 4. Hypothesized Anthropocentric Misconception Statement: "Bacteria develop resistance to antibiotics because of changes within humans in response to an antibiotic medication." Among students, 57\% indicated agreement with the anthropocentric statement (Figure 4D). A small but significant difference in agreement was seen between EBM (64\%) and ABM $(50 \%)\left(\chi^{2}=6.646, N=426, p=0.0099\right)$. NBM were not significantly different from other student groups at $57 \%$ agreement. No BF agreed with this statement, a significant variation from all student groups $(p<0.0001)$.

Intuitive Reasoning Produced in Response to Misconception Statements. Intuitive reasoning was produced by a majority of 


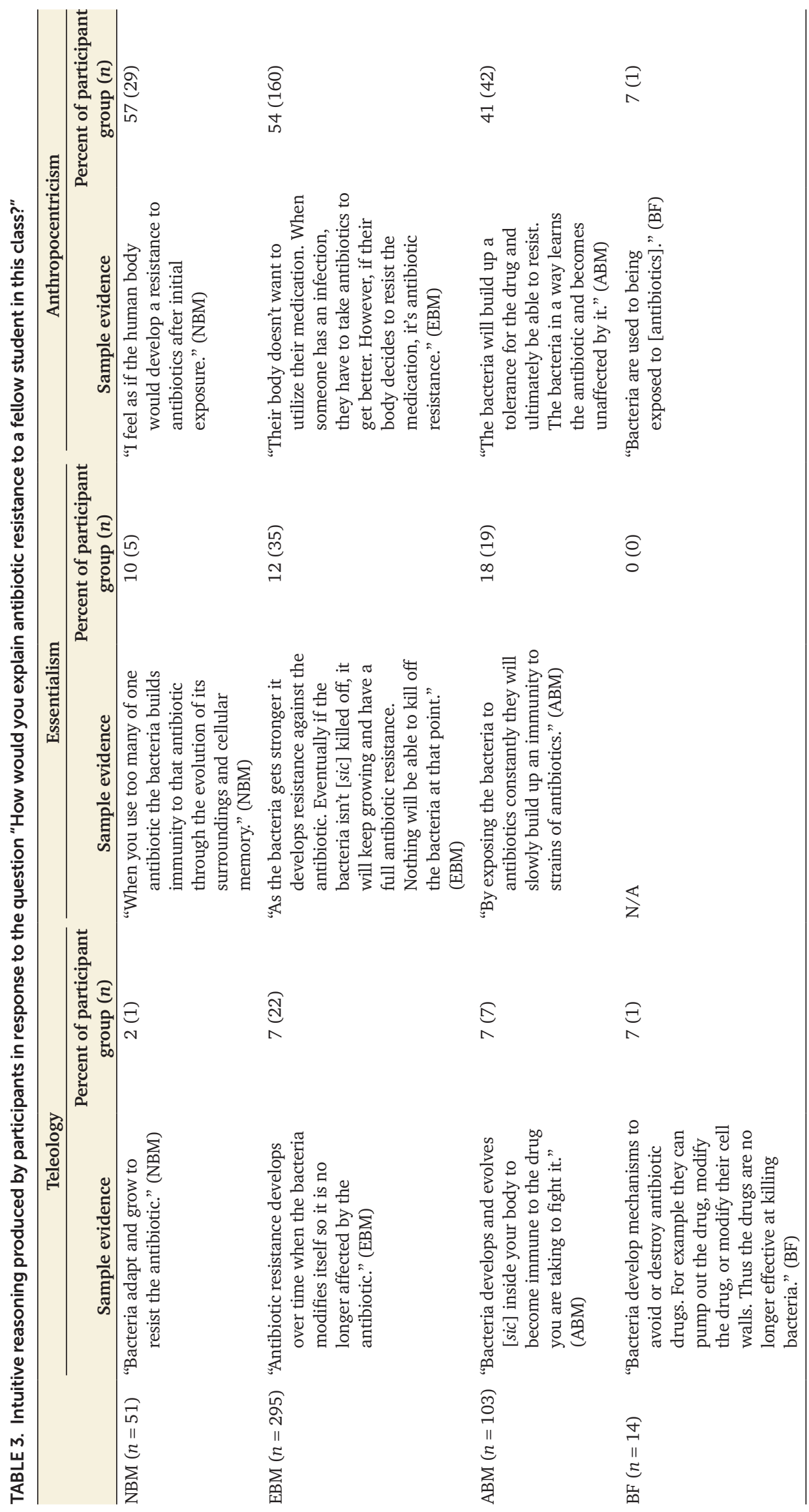


"How would you explain antibiotic resistance to a fellow student in this class/to a professional colleague?"

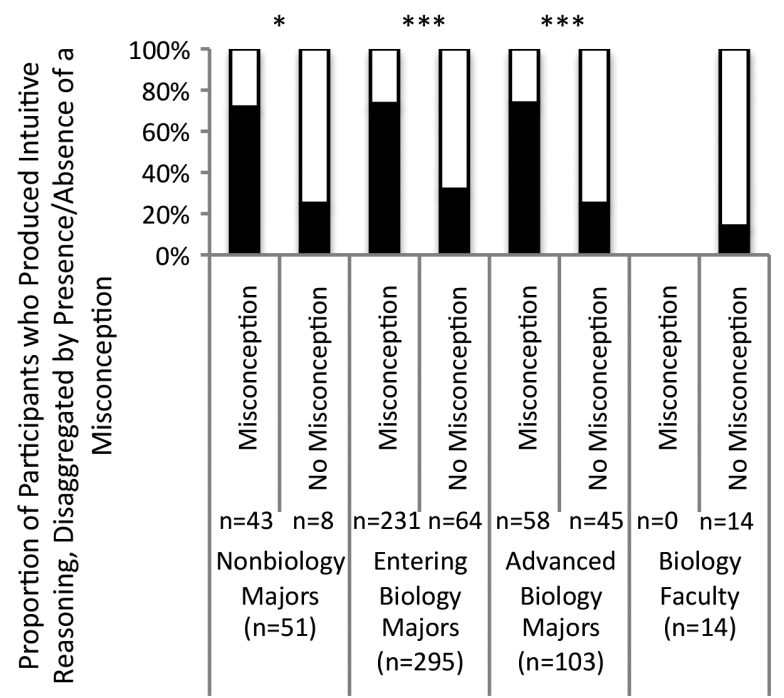

FIGURE 3. Production of intuitive reasoning, disaggregated by presence and absence of one or more misconceptions (black bars), in response to unframed assessment item 1: "How would you explain antibiotic resistance to a fellow student in this class/to a professional colleague?" *, $p<0.05 ;{ }^{* *}, p<0.0001$.

students in their written explanations for their positions on the misconception statements: more than $90 \%$ of all students ( $91 \%$ of NBM; $91 \%$ of EBM; $89 \%$ of ABM evidenced some form of intuitive thinking at least once in these responses. Overall, $14 \%$ of $\mathrm{BF}$ produced at least one instance of intuitive reasoning (Figure 5A). Each form of intuitive reasoning was coded independently, and multiple forms could be present within a participant's response or within a single quote. Overall production of each form of intuitive reasoning was similar across all student populations. Findings relating to each form of intuitive reasoning are detailed below.

Teleological Reasoning Produced in Response to Assessment Item 2 (Hypothesized Teleological Misconception Statement): "Individual bacteria develop mutations in order to become resistant to an antibiotic and survive." In response to the hypothesized teleological misconception statement, $41 \%$ of all students used teleological reasoning in their writing: $41 \%$ of NBM, $46 \%$ of EBM, and $35 \%$ of ABM evidenced some form of intuitive thinking at least once in these responses (Figure 5B). No faculty member used teleological language in response to this item. The presence of writing that evidenced attribution of a change to a goal, purpose, or need was coded as teleological; representative quotes from each population are shown here. Additional quotes are displayed in Supplemental Table 1.

\footnotetext{
"Bacteria mutate to better resist antibiotics. Bacteria being a species that procreates, mutates to survive and to be able to continue procreating." (NBM)

"This is survival instinct. Bacteria is attacked by antibiotics and has to adapt in order to survive. The way in which it adapts in this instance is that it has to mutate in order to subside or completely negate the antibiotics." (EBM)
}

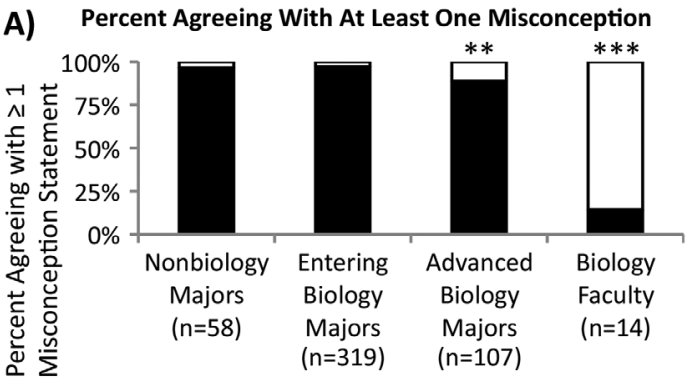

B) "Individual bacteria develop mutations in order to B) become resistant to an antibiotic and survive."

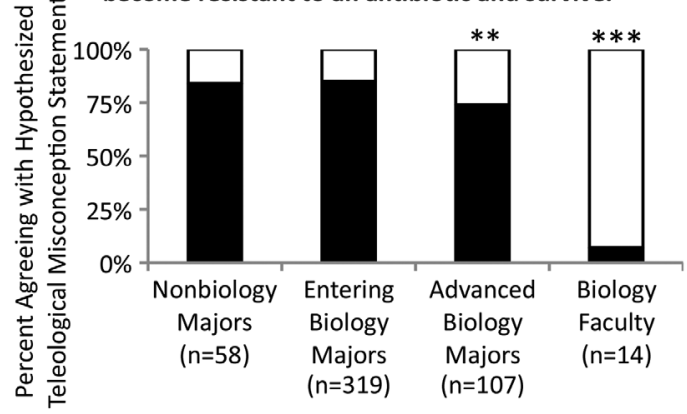

C) "Individual bacteria are genetically similar and equally

C) likely to be killed off by an antibiotic medication."
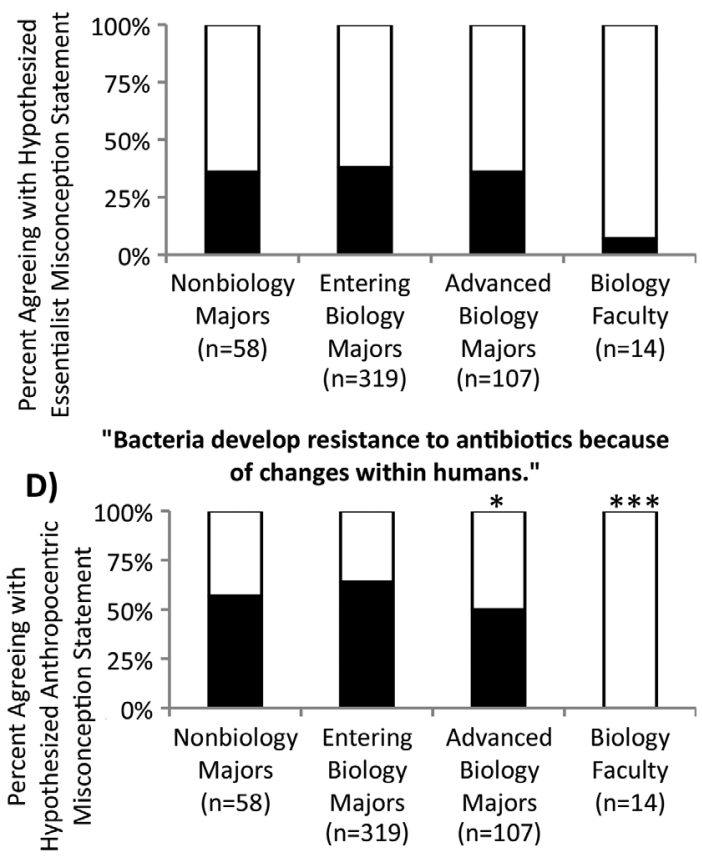

FIGURE 4. Participant agreement (black bars) with hypothesized intuitive reasoning-based misconception statements. (A) Participant agreement to one or more of the three misconception statements. (B) Participant agreement in response to the hypothesized teleological misconception: "Individual bacteria develop mutations in order to become resistant to an antibiotic and survive." (C) Participant agreement in response to hypothesized essentialist misconception: "Individual bacteria are genetically similar and equally likely to be killed off by an antibiotic medication." (D) Participant agreement in response to hypothesized anthropocentric misconception: "Bacteria develop resistance to antibiotics because of changes within humans." ${ }^{*}, p<0.05$; $* *, p<0.01 ; * * *, p<0.0001$. 


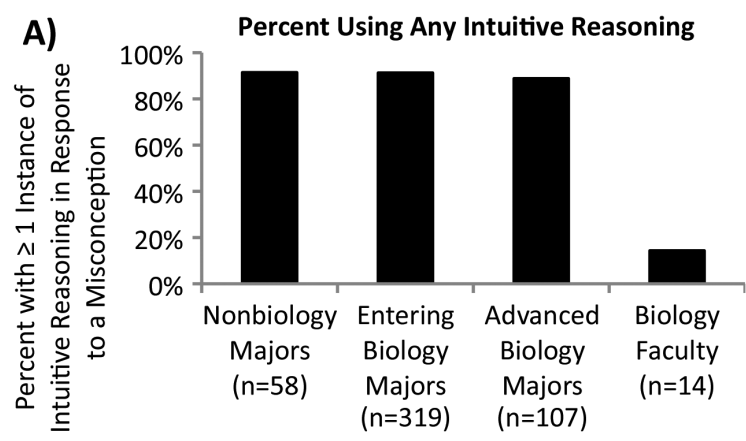

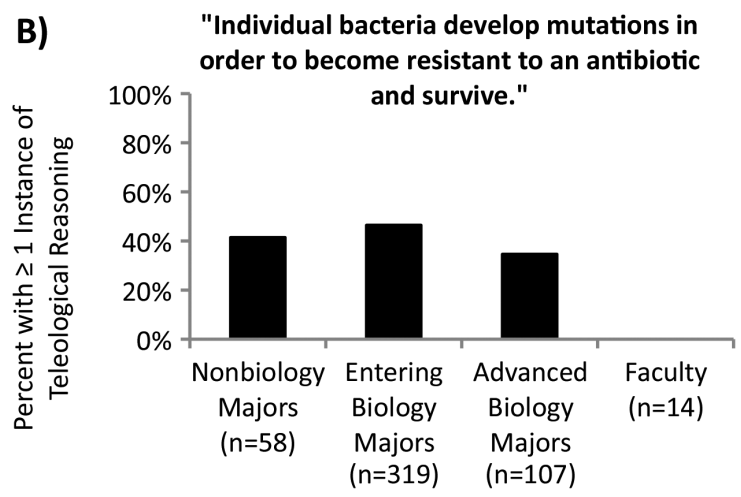
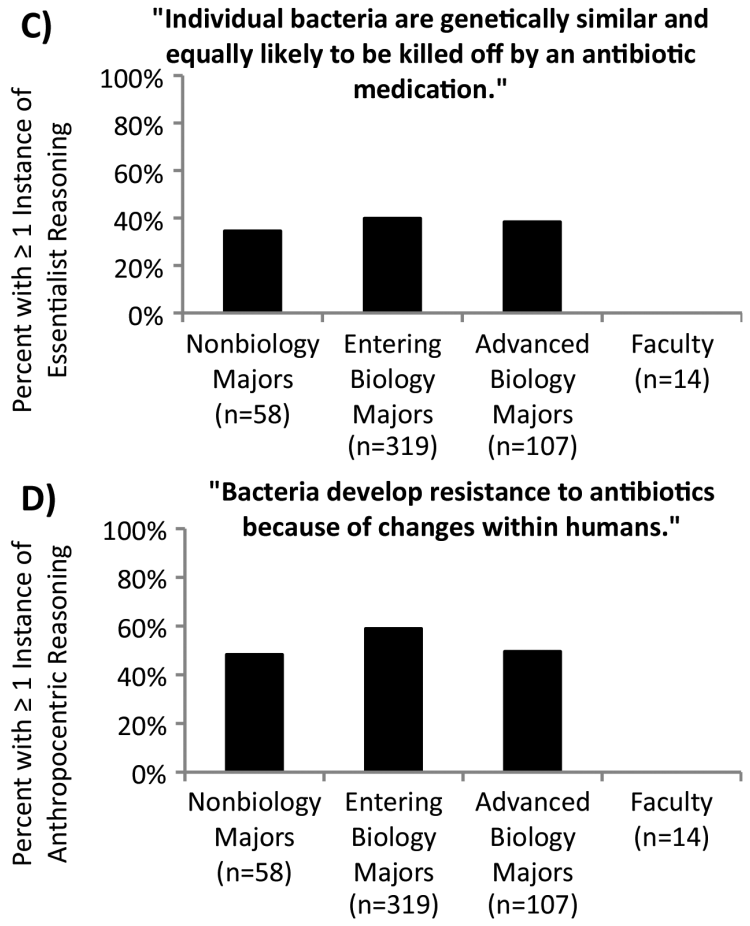

FIGURE 5. Production of the hypothesized form of intuitive reasoning in response to each misconception statement. (A) Percentage of each population to use any form of intuitive reasoning in response to any of the three misconception statements. (B) Percentage of each population with at least one instance of teleological reasoning in response to the teleological statement. (C) Percentage of each population with at least one instance of essentialist reasoning in response to the essentialist misconception statement. (D) Percentage of each population with at least one instance of anthropocentric reasoning in response to the anthropocentric statement. Note: In the few instances where faculty
"I describe the antibiotic resistance phenomenon as the bacteria evolving to survive." (ABM)

Essentialist Reasoning Produced in Response to Assessment Item 3 (Hypothesized Essentialist Misconception Statement): "Individual bacteria are genetically similar and equally likely to be killed off by an antibiotic medication." In response to the hypothesized essentialist misconception statement, $37 \%$ of all students evidenced essentialism in their writing: $34 \%$ of NBM, $40 \%$ of EBM, and $38 \%$ of $\mathrm{ABM}$ evidenced some form of intuitive thinking at least once in these responses (Figure 5C). No faculty member produced essentialist language in response to this item. The presence of writing that homogenized bacterial populations and disregarded the role of variability were coded as essentialist. Sample student quotes are shown here and in Supplemental Table 2.

"If bacteria reproduces [sic] by cloning then they would all be equally likely to be killed by antibiotics because they would just be multiple copies of the same bacteria." (NBM)

"Bacteria are made up of all the same things. More than likely they can be killed off by an antibiotic medication." (EBM)

"Like humans, we have different skin colors but we have almost the same genes. That's why the bacteria are genetically similar and equally likely to be killed off by an antibiotic medication." (ABM)

Anthropocentric Reasoning Produced in Response to Assessment Item 4 (Hypothesized Anthropocentric Misconception Statement): "Bacteria develop resistance to antibiotics because of changes within humans in response to an antibiotic medication." In response to the hypothesized anthropocentric misconception statement, $45 \%$ of all students used anthropocentric reasoning in their writing: $48 \%$ of NBM, $59 \%$ of EBM, and $50 \%$ of $\mathrm{ABM}$ evidenced some form of intuitive reasoning at least once in these responses (Figure 5D). No faculty member used anthropocentric language in response to this item. Anthropocentricism primarily manifested in two ways in these data: writing that inappropriately attributed human traits or actions to bacteria (anthropomorphism, or personification) and overemphasis of human importance to the process of antibiotic resistance (anthropocentricism). Sample student quotes from each of these categories are shown here and can be found in Supplemental Table 3.

Examples of anthropomorphism:

"Bacteria can come together to be powerful and therefore fight off the antibiotic. Once they know what an antibiotic is, they will know how to fight it." (EBM)

"Bacteria want to continue to live so they become genetically favorable to live in an environment where antibiotics are present." (ABM)

produced intuitive reasoning, it was never the form hypothesized to be associated with the misconception statement. This is reflected in a positive faculty value in $A$ but zero values for $B-D$. 


\section{Examples of anthropocentrism:}

"I don't think bacteria develop resistance to antibiotics. I think some individuals could already be born with antibiotic deficiency. Some could also develop resistance to antibiotic from other medications that could change one's body system." (EBM)

"Humans react a certain way to the medication which then will trigger the bacteria and make it resistant as well." (ABM)

Relations between Agreement with a Misconception Statement and Production of Intuitive Reasoning. To investigate potential links between misconceptions and underlying intuitive reasoning, we looked for associations between participants' agreement with a misconception statement and their use of the form of intuitive reasoning hypothesized to be connected with that statement. For all student populations and across all misconception statements, a significant association was seen between a student's agreement with a misconception and evidence of intuitive reasoning in his or her writing (all $p$ $<0.05$; Figure 6). While faculty evidenced some instances of intuitive reasoning and rarely agreed with a misconception, no associations were seen within faculty on any misconception statement. That is, if a faculty member evidenced a form of intuitive reasoning, it was never the form hypothesized to be related with the misconception statement his or her response addressed. Statistical relationships between agreement with a misconception and use of a hypothesized form of intuitive reasoning are detailed below by misconception statement.

Relations on Assessment Item 2. Hypothesized Teleological Misconception Statement: "Individual bacteria develop mutations in order to become resistant to an antibiotic and survive." As shown in Figure 6A, NBM who agreed with our hypothesized teleological misconception statement were significantly more likely to produce teleological reasoning $\left(\chi^{2}=4.024, N=58, p=0.0449\right)$ than were participants who disagreed with the statement. The use of intuitive reasoning was also significantly related with agreement for EBM $\left(\chi^{2}=16.453, N=319, p<0.0001\right)$ and $\mathrm{ABM}\left(\chi^{2}=4.688, N=107, p=0.0304\right)$.

Relations on Assessment Item 3. Hypothesized Essentialist Misconception Statement: "Individual bacteria are genetically similar and equally likely to be killed off by an antibiotic medication." Figure 6B shows associations in all groups between agreement with our hypothesized essentialist misconception statement and use of essentialist reasoning. NBM who agreed with our hypothesized essentialist misconception statement were significantly more likely to produce essentialist reasoning in their writing $\left(\chi^{2}=11.143, N=58, p=0.0008\right)$. The use of intuitive reasoning was also significantly associated with agreement for EBM $\left(\chi^{2}=79.655, N=319, p<0.0001\right)$ and ABM $\left(\chi^{2}\right.$ $=14.920, N=107, p=0.0001)$.

Relations on Assessment Item 4. Hypothesized Anthropocentric Misconception Statement:"Bacteria develop resistance to antibiotics because of changes within humans in response to an antibiotic medication." Figure 6C shows associations between agreement of the anthropocentric misconception statement and use of anthropocentricism in participants' written reasoning. NBM who agreed with our hypothesized anthropocentric misconception
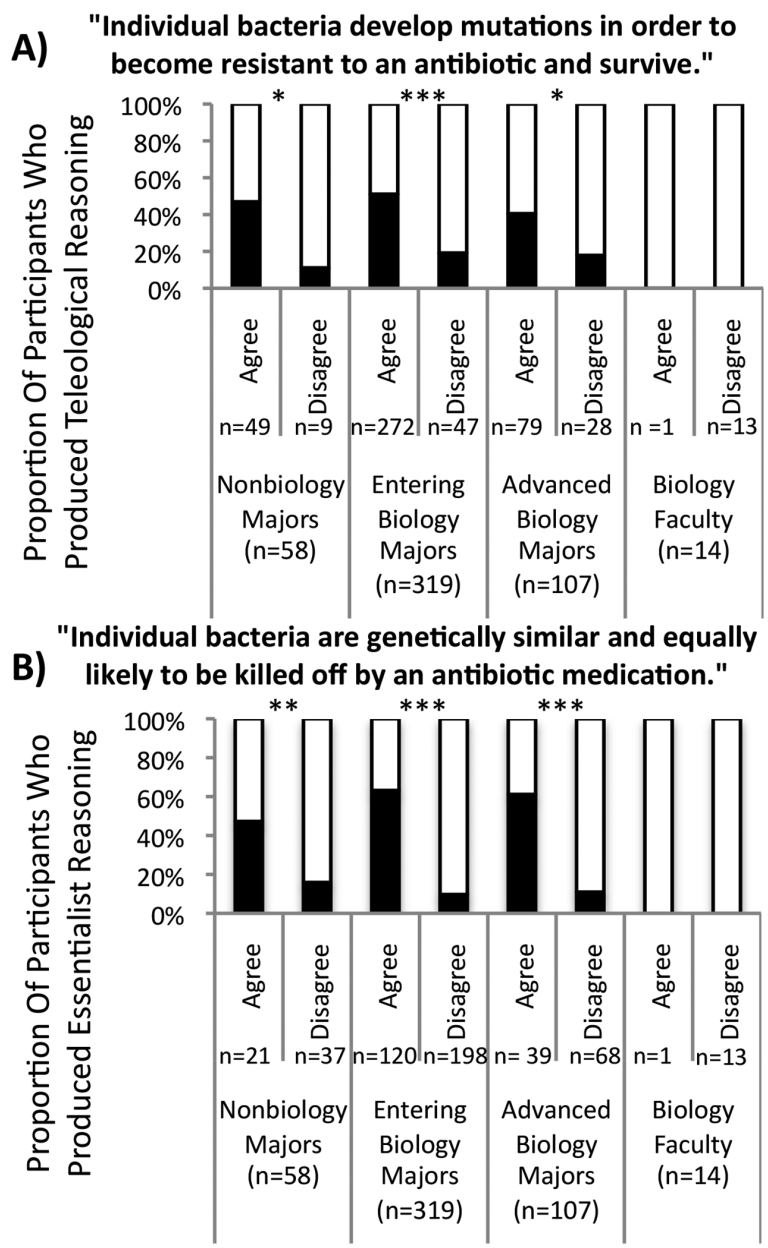

"Bacteria develop resistance to antibiotics because of changes within humans."

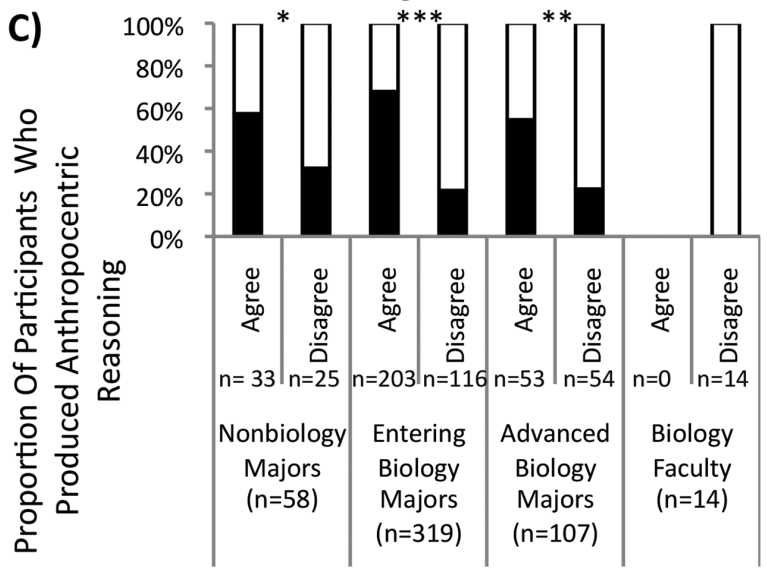

FIGURE 6. Proportion of participants who produced the hypothesized form of intuitive reasoning (black bars), disaggregated by agreement with misconception statement. White bars indicate participants who did not produce intuitive reasoning. (A) Participant production of teleological reasoning in response to the hypothesized teleological misconception statement. (B) Participant production of essentialist reasoning in response to the hypothesized essentialist misconception statement. (C) Participant production of anthropocentric reasoning in response to the hypothesized anthropocentric misconception statement. ${ }^{*}, p<0.05 ;{ }^{* *}, p<0.01 ;{ }^{* *}, p<0.0001$. 
statement were significantly more likely to also produce anthropocentric language $\left(\chi^{2}=5.471, N=58, p=0.0193\right)$. The use of intuitive reasoning was also significantly related to agreement for EBM $\left(\chi^{2}=61.356, N=319, p<0.0001\right)$ and ABM $\left(\chi^{2}=\right.$ $11.775, N=107, p=0.0006)$.

\section{Assessment Item 5. Evolution-Framed Statement:}

"Antibiotic resistance is an example of evolution"

To investigate how participants applied their knowledge of evolution to their reasoning on antibiotic resistance, we examined student responses to two items in our assessment tool. We analyzed participants agreement with an evolution-framed assessment (item 5), which prompted participants to agree or disagree with a statement positing antibiotic resistance as an example of evolution. We also coded participants' initial explanations of antibiotic resistance for evidence of natural selection knowledge in response to our initial, unframed prompt (assessment item 1). Below are the analyses of each of these items.

\section{Agreement with Antibiotic Resistance as an Example of} Evolution. In response to our prompt directly asking participants to consider a link between evolution and antibiotic resistance, 91\% of all students agreed (NBM, 90\%; EBM, 91\%; ABM, $91 \%$ ) and $93 \%$ of faculty agreed (Figure 7 ). There were no significant differences between student groups or between students and faculty in response to this prompt. However, while a majority of students agreed with this prompt, many students' written responses included additional misconceptions about evolution and evidence of intuitive reasoning. Few students provided scientifically accurate explanations of natural selection or antibiotic resistance. Presented here are a range of sample quotes from participant responses explaining their agreement with the prompt "Antibiotic resistance is an example of evolution."

"Evolution can have several classifications. When your body becomes resistant to medication, something has changed. It can be mutations or a body reaction. Regardless this is a change to your body which would in a way classify it as a small evolution." (NBM)

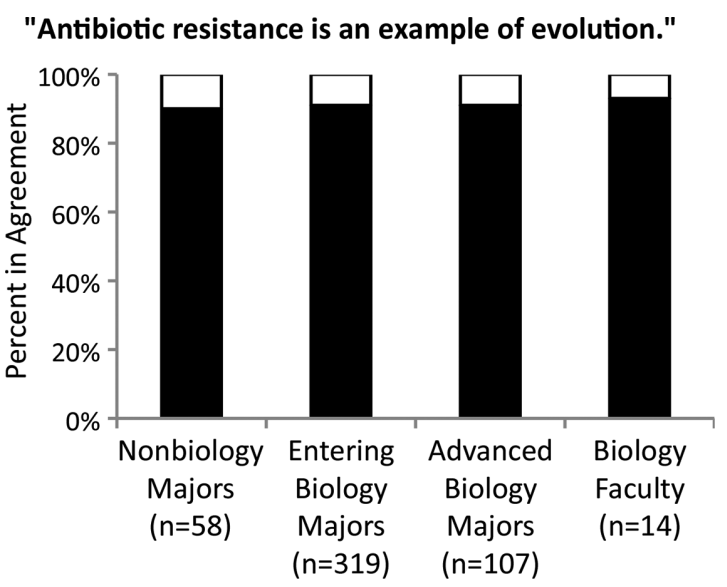

FIGURE 7. Participant responses to the evolution-framed assessment item 5: "Antibiotic resistance is an example of evolution." Black bars, agreement; white bars, disagreement. No statistically significant differences among populations.
"Natural selection and evolution is about improved means of survival." (NBM)

"Yes it is an example of evolution because evolution is about experience and it causes things to change because of it. If the bacteria is being recognized by the antibiotic medication then it is going to try and change its genetics or form in order to better 'hide' itself." (EBM)

"Yes it is an example of evolution. The bacteria has evolved to overcome an obstacle. It is natural selection. If you can't outbeat a predator, you die. So you must evolve to survive. That is exactly what bacteria does." (ABM)

"If I have 1000 bacteria and add an antibiotic and kill 999, the one that survived has the trait that kept it alive in its DNA. As this new 'strain' of bacteria reproduces it makes more that have this trait." (EBM)

"Antibiotics put selective pressure on populations of bacteria-those that are naturally resistant will grow and reproduce. Those bacteria that are not 'fit' to reproduce (because they get killed off by the antibiotic) will die off and not survive." (BF)

Application of Natural Selection Knowledge in Unframed Explanations of Antibiotic Resistance. As explained in Methods, we used the presence of discussion of variability and differential survival as a measure for presence of the application of natural selection knowledge in response to the unframed assessment item 1: "How would you explain antibiotic resistance to a fellow student in this class/to a professional colleague?" In Figure 8, we see evidence that only a minority of students in all populations referenced aspects of natural selection knowledge in their initial explanations. In students' initial explanations of antibiotic resistance, only $28 \%$ of $\mathrm{ABM}$ and $10 \%$

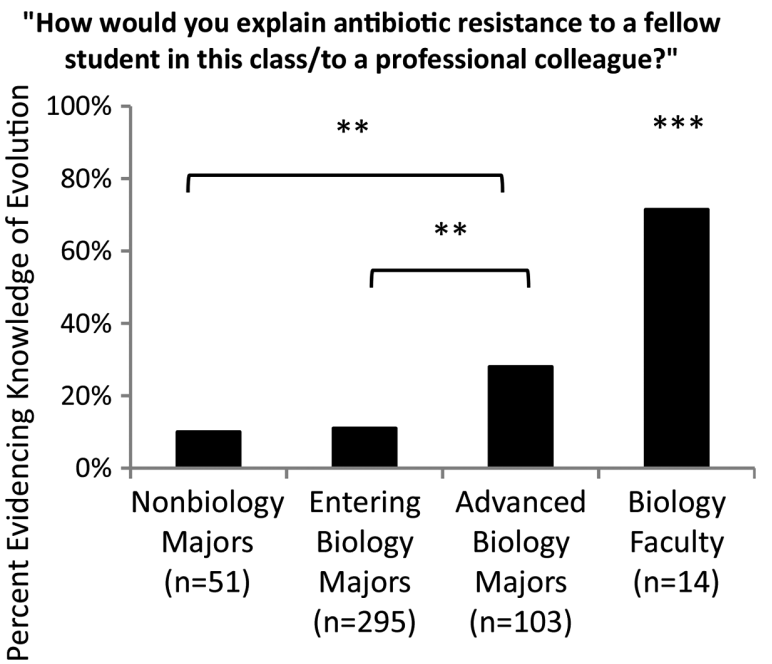

FIGURE 8. Evidence of evolutionary knowledge in participant responses to the unframed assessment item 1: "How would you explain antibiotic resistance to a fellow student in this class/to a professional colleague?" $* * *, p<0.001$ between $\mathrm{BF}$ and all student populations; ${ }^{* *}, p<0.01$ between ABM and both NBM and EBM populations. 
and $11 \%$ of NBM and EBM, respectively, attributed differential survival as playing a role in antibiotic resistance. Significantly more BF (71\%) included aspects of evolutionary knowledge in their responses compared with all student populations (all $p<$ 0.0001). ABM also referenced aspects of evolutionary knowledge significantly more than NBM $\left(\chi^{2}=6.677 N=154, p=\right.$ $0.0098)$ and EBM $\left(\chi^{2}=18.570, N=398, p<0.0001\right)$. Sample quotes indicating evolutionary knowledge are shown here: "Germs that are susceptible to this antibiotic are eliminated
leaving the field open for proliferation of resistant germs."
(NBM)

"If the antibiotics introduced into the system are unable to kill some bacteria, that bacteria is allowed to thrive and reproduce more bacteria cells similar to its own." (EBM)

"[Antibiotic resistance] results because some small strain of microorganisms were able to survive due to some type of mutation while under drug treatment. This species yields offspring that carry this trait." (ABM)

"The bacteria that can develop these genetic mutations that facilitate their survival [will] live, and can pass on their genetic material." (BF)

\section{DISCUSSION}

Biology education researchers have documented persistent scientifically inaccurate ideas, often termed "misconceptions," in several biological domains. Cognitive and developmental psychologists have likewise described intuitive conceptual patterns-teleological, essentialist, and anthropocentric thinking - that humans develop at an early age to reason about biology. Interdisciplinary psychology and science education research has explored the hypothesis that seemingly unrelated biological misconceptions may have common roots in these intuitive ways of knowing (Coley and Tanner, 2012, 2015).

In this study, we further investigated the relations between misconceptions and intuitive reasoning in the context of antibiotic resistance and evolution, addressing the following research questions: 1) To what extent do undergraduate students with various levels of formal biology education embrace misconceptions of antibiotic resistance, a contextualized example of natural selection? 2) To what extent do students evidence intuitive reasoning in their written explanations of antibiotic resistance? 3) How is intuitive reasoning related to misconceptions, and are those relations the same for various student groups and faculty? 4) How do students and faculty apply knowledge of natural selection in the context of antibiotic resistance? In the following sections, we explore six key findings, along with the implications of our results and potential future research directions.

\section{The Majority of Students Embrace Misconceptions about Antibiotic Resistance}

In their initial written explanations, students produced many misconceptions about the nature of antibiotic resistance, and many students in all populations agreed with misconceptions when presented with them. One of the most common misconceptions produced by students without prompting was the idea that antibiotic resistance was due to a change within the human body, rather than due to changes within bacterial populations. Some examples of this misconception included the idea that the human body develops tolerance to antibiotics akin to pain medication or alcohol, that human allergies play a role in antibiotic resistance, that a change in humans at the genetic or cellular level contributes to resistance, or that diet and exercise habits impact antibiotic resistance. A recent World Health Organization report on public awareness of antibiotic resistance also found the idea that the body becomes resistant to antibiotics to be a commonly held misconception (World Health Organization, 2015). A majority of participants (76\%) across all included countries indicated agreement with the statement "Antibiotic resistance occurs when your body becomes resistant to antibiotics and they no longer work as well." The idea that the human body is the primary target of antibiotics was also expressed by $50 \%$ of firstyear medical students in a study of misconceptions on natural selection in medical biology students (Brumby, 1984). This finding was presumably unanticipated, as the author notes, "The antibiotic problem proved extremely difficult to be recognized [by participants] as a problem based on natural selection." Generally, past studies on public knowledge of antibiotics in the United States have tended to focus on patients' habits in taking medications rather than probing for public understanding of the mechanisms behind antibiotic function or the phenomenon of antibiotic resistance (McNulty et al., 2007; Huttner et al., 2010). Our results showed a prevalence of misconceptions about antibiotic resistance in populations of undergraduate students, including those having completed course work in advanced biology and genetics. This persistence of misconceptions among even $\mathrm{ABM}$ suggests that fundamental misunderstandings about the nature of antibiotic resistance are likely common among the public as well. Antibiotic resistance continues to present a significant global issue in medicine, and our results shed light on the prevalence of misconceptions potentially impacting public perceptions of antibiotic use and prescription.

Intuitive Reasoning Was Common in All Student Responses Intuitive reasoning of many forms was found throughout student responses, both in initial explanations of antibiotic resistance and in response to misconception statements. While we hypothesized each of our misconception statements to elicit a specific form of intuitive reasoning, many students produced other types in addition to the hypothesized form. Intuitive thinking has been studied extensively in young children; however, its presence in the reasoning of older individuals and those at higher educational levels has been far less investigated (Coley, 2000). Our results, based on the consensus of multiple trained coders, showed that nearly all students used some form of intuitive reasoning - teleology, essentialism, or anthropocentricism-at least once in their written responses. Our findings show these types of reasoning are widely present in university students, including within ABM.

Alongside the three main types of intuitive reasoning we investigated-teleology, essentialism, and anthropocentricism-a number of additional, nuanced subcategories of intuitive reasoning also emerged in student writing. For instance, anthropomorphism, or attributing human abilities to bacteria, commonly coincided with teleological reasoning, with individuals attributing a human-specific action or trait to provide the means of an organism realizing a teleological goal. This 
"effort-based" view, in which individual organisms act in goal-directed ways to meet their needs, often underlies students' needbased descriptions of adaptation and selection (Tamir and Zohar, 1991; Kelemen, 2011). In student writing, this "anthroteleo" approach manifested as descriptions of bacteria as wanting, trying, fighting, and even collaborating and learning in some responses as a reaction to antibiotics and a means of achieving antibiotic resistance. The modal system of the English language has been suggested to implicitly lend itself to both teleological and anthropocentric explanations of science (Sealey and Oakley, 2014).

Frequently, teleological and anthropocentric reasoning preclude explanations that allow for acknowledgment of the role of genetic variability in evolution (Alters and Nelson, 2002; Evans, 2008). The exclusion of variation in participants' responses manifested as essentialist reasoning in a variety of ways. For the purposes of this investigation, we limited analysis of essentialism to responses that discussed bacterial populations as homogenous or static, where variability was absent or disregarded. However, a small proportion of responses in all student populations also produced language that appeared to represent a "boundary intensification" form of essentialism (Gelman and Rhodes, 2012; Gelman and Ware, 2012). Related to essentialist ideas that categories are stable and homogenous is the idea that categorical boundaries are strict and impermeable. Bacterial categories described by students sometimes related to features such as the "seriousness" of a bacterial infection to a person; whether bacteria were "old" or "new," "mutated," "not mutated," or "good" or "bad" for the human body; and the idea that each "kind" of bacteria required its own unique antibiotic. Student responses that expressed this type of essentialism discussed variability, but only in the context of discrete, internally homogenous, and static categories of bacteria. This contrasts with an acknowledgment of variability along a continuum or conveying the idea that bacteria could share many characteristics while still being dissimilar in important ways. These more nuanced forms and intersections of intuitive reasoning were unanticipated and speak to the complexity of forms of intuitive reasoning and ways in which this reasoning may relate to misconceptions.

\section{Student Misconceptions Were Significantly Associated with the Use of Intuitive Reasoning}

A student's agreement with a misconception statement was significantly correlated with that individual's production of the hypothesized form of intuitive reasoning, regardless of student group or the specific misconception. Notably, this association was seen even in initial explanations of antibiotic resistance, before students encountered any of our misconception statements or intuitive reasoning prompts. Students' novel production of any misconception and their production of any form of intuitive reasoning in their writing showed correlations similar to the relationships measured on our misconceptions statements. While student-produced misconceptions varied widely, the observation that they still were significantly likely to be associated with a form of intuitive reasoning supports our hypothesis that intuitive reasoning may be a potential root of these misunderstandings. Interestingly, the relationship between a form of intuitive reasoning and the hypothesized related misconception also persisted even on the essentialist misconception, which had relatively low agreement rates in all student groups compared with the other two misconceptions. Even in response to a misconception statement more widely recognized as false, students who did embrace the misconception were still more likely to produce essentialist reasoning. Previously, a Coley and Tanner (2015) investigation also found positive associations between specific forms of intuitive reasoning and agreement with biological misconceptions across various contexts. In their study, essentialist misconception statements also had relatively lower proportions of students in agreement, and correlations between agreement and use of essentialist reasoning in written responses among EBM were also still observed. Our findings regarding the persistence of a relationship between intuitive reasoning and misconceptions throughout biology education support the hypothesis that intuitive reasoning is frequently linked to misconceptions.

\section{In Contrast to Previous Investigation, Associations between Intuitive Reasoning and Misconceptions Were Observed across All Student Groups}

We found similar correlations between misconceptions and their specific hypothesized form of intuitive reasoning across all student groups, including NBM. This contrasts with Coley and Tanner's (2015) investigation of potential relationships between misconceptions and intuitive reasoning. In this previous study, correlations between intuitive reasoning and agreement with a misconception hypothesized to be rooted in that form of reasoning were "very specific and precise" in biology majors only. That is, for biology majors, the presence of teleological reasoning in written explanations was associated exclusively with agreement with teleological misconception statements, and frequency of essentialist reasoning in written explanations was associated exclusively with agreement with essentialist misconception statements, and so on. For nonmajors in this prior study, however, the overall frequency of intuitive reasoning in written explanations was unrelated to their agreement with a corresponding misconception statement. These previous results raised the possibility that formal biology education may somehow reify the links between intuitive reasoning and biological misconceptions (Coley and Tanner, 2015). In our findings, however, significant and specific associations were observed in all populations and on all intuitive reasoning-framed assessment items. Differences between this study's methodology and that of the previous study may account in part for the contrast in our findings regarding biology majors and nonmajors. Here, our participant populations were recruited from a diverse, public university, and our sample included an advanced biology major group in addition to the EBM and NBM groups. The Coley and Tanner (2015) prior investigation sampled from a selective private university and controlled for high school background, where entering biology major student participants had earned Advanced Placement (AP) credit in biology and NBM had earned AP credit in a subject other than biology. This difference could perhaps mean the results of the previous study were obtained from populations with overall more extensive formal course work in biology or, potentially, other sciences. Additionally, the format of Coley and Tanner's (2015) assessment examined intuitive reasoning and agreement with misconceptions across 12 different contexts spanning human, animal, and plant biology. Our assessment took a deeper look into a single 
context-antibiotic resistance-and examined student misconceptions and application of intuitive reasoning within this topic only. The context of the assessment prompts may likely play a role in participants' perceptions and problem-solving processes (Nehm and Ridgeway, 2011). Furthermore, our assessment asked students whether they had ever studied the topic of antibiotic resistance as part of previous course work, and more than half of student participants had not (unpublished data). The hypothesis that formal biology education may reinforce the associations between intuitive reasoning and misconceptions was not supported here; however, the conceptual focus of our study may have been beyond most of our participants' previous course curricula. Associations between intuitive reasoning and misconceptions of antibiotic resistance would not have been driven by formal biology education if antibiotic resistance was not taught to the students in our study. Our findings, in contrast with some of those from the previous investigation, raise questions about the role that context, topic, and formal instruction may play in how intuitive reasoning relates to student misconceptions.

\section{Undergraduate Education Does Not Appear to Affect Students' Understanding of Antibiotic Resistance or Use of Intuitive Reasoning}

$A B M$ were in many measures not significantly different from EBM and NBM, though we hypothesized that greater differences would be evident. ABM showed similar levels of intuitive reasoning, agreed with misconceptions in proportions comparable with other student groups, and also had significant correlations between their production of intuitive reasoning and agreement with misconceptions. Differences between ABM and EBM and NBM, while significant in some measures, were surprisingly minimal, given that the $\mathrm{ABM}$ group had completed all required core course work for a biology major up though the completion of a genetics course. Prior study of undergraduate learning has made clear not only the specific challenges of successfully addressing misunderstandings of evolution in science education but also the overall struggle on college campuses to ensure students gain experience in complex reasoning (Arum and Roksa, 2011). Instructional strategies that compartmentalize evolution and focus primarily on memorization of content are increasingly found to be ineffective at promoting learning of complex biological concepts (Nehm et al., 2008; Speth et al., 2014). Our study adds to the body of evidence that many college students struggle to scientifically conceptualize evolution and that this lack of understanding can extend throughout college education, within the biology major, and perhaps beyond graduation.

\section{While Most Students Agreed That Antibiotic Resistance Is an Example of Evolution, Few Demonstrated Accurate Understanding of Natural Selection}

All student groups and faculty indicated nearly identical agreement with the statement "Antibiotic resistance is an example of evolution." However, there was little evidence in written responses of students accurately conceptualizing the connection between selection and antibiotic resistance. In initial explanations of antibiotic resistance, few student responses included discussions of selection or descriptions of variability and differential survival. Additionally, even in explanations written by students who agreed that antibiotic resistance is an example of evolution, many students expressed evolutionary misconceptions and evidence of intuitive reasoning (unpublished data). Evolution education remains largely fragmented from other biology teaching, despite calls for more thorough integration into classroom topics (Speth et al., 2014). Textbooks and curricula frequently isolate evolutionary topics, resulting in courses that "neither foster accurate mental models of evolution's mechanisms nor instill an appreciation of evolution's centrality to an understanding of the living world" (Nehm et al., 2008, p. 528). Misconceptions about evolution persist throughout undergraduate biology education, and rather than advanced instruction addressing misunderstandings, students are often left to apply scientific information to an alternate, "preconception" framework based in inaccurate understandings. Students in both our study and other studies frequently exhibit both scientific and alternate conceptions alongside one another, adding evidence pointing to the unconscious and intuitive nature of alternative conceptual frameworks. Kampourakis and Zogza (2008) call for future study in evolution education to investigate the impacts of presenting students with opportunities for "cognitive conflict," in which major components of existing conceptual frameworks could be challenged and replaced by scientifically accurate ones.

\section{Hypothesized Mechanisms Underlying Intuitive Reasoning-Based Misconceptions}

While faculty infrequently produced intuitive reasoning in their writing, the unintentional, unconscious use of intuitive language in teaching may contribute to students' retention of misconceptions. When participating BF did use intuitive reasoning, it was not correlated with production or agreement with a misconception related to that form of reasoning. This absence of a correlation is striking, in that it highlights the potential appeal of intuitive reasoning as "verbal shorthand," despite its potential inaccuracy. Faculty overwhelmingly recognized and rejected our misconception statements and largely provided scientifically complete written responses; however, these responses may not be representative of what faculty say aloud in classrooms. The resilience of intuitive reasoning may likely persist across the life span, even in professional scientists. Whether advanced study and specialization in science can in itself remove scientifically inaccurate frameworks about the natural world is an ongoing area of study. Evidence does, however, show that in circumstances in which cognitive processing is limited, that is, under a time constraint, adults are more likely to accept inaccurate explanations rooted in teleology and other intuitive frameworks despite a high accuracy rate in unrestricted circumstances (Kelemen and Rosset, 2009; Kelemen, 2011; Shtulman and Valcarcel, 2012; Shtulman and Harrington, 2015). Furthermore, as noted by Sealey and Oakley (2014), common usage patterns of the English language frequently tend toward inherent teleological and anthropomorphic explanations. Essentialism is also reflected in everyday language patterns, with phrases like "birds fly" and other generic noun phrases offering shorthand generalizations that ignore within-category variability (Cimpian and Markman, 2009; Gelman and Rhodes, 2012). The presence of such nonliteral explanations, which contribute to intuitive conceptions, is a common feature in science media, including textbooks (Nehm et al., 2010). While instructors and even many students may be able to distinguish between intuitive linguistic formulations and factual scientific explanations of biological phenomena, making 
distinctions between the two can be complex and challenging for biology novices (Tamir and Zohar, 1991). While figurative expressions are common, the ambiguity they add to explanations of scientific processes may be more confounding than helpful in promoting student understanding. Whereas experts can differentiate between multiple possible meanings, research in several domains suggests that students cannot (Nehm et al., 2010).

\section{Future Directions}

Our findings point to the continued potential for investigating intuitive conceptual frameworks as a means of understanding and addressing common evolutionary and biological misconceptions. Our findings regarding the links between forms of intuitive reasoning and misconceptions support the hypothesis that intuitive reasoning may underlie systems of biological misconceptions. The impact that formal biology education may have on associations between intuitive reasoning and misconceptions remains unclear, as our findings varied from previous work on these relationships. Future work could probe intuitive reasoning more deeply in other contexts and further explore the links between intuitive reasoning and misconceptions at various levels of biology education. It is likely that associations may be thoroughly ingrained in students far before undergraduate biology classrooms (Inagaki and Hatano, 2002, 2006; Kelemen, 2011). Future studies could continue to investigate the relationships between intuitive reasoning and misconceptions in additional contexts, such as within the same student populations longitudinally in students or at additional institutions.

\section{CONCLUSIONS}

Our findings here expand upon those seen in previous investigations of intuitive reasoning in biology classrooms and their potential links to common misconceptions. We found that students produced and agreed with multiple biological misconceptions of antibiotic resistance, evolution, and natural selection, with only moderate decreases seen with advanced biology student populations. Additionally, all student populations evidenced prevalent use of intuitive reasoning, including teleological, essentialist, and anthropocentric thinking, throughout their written responses. Strong relationships were seen in all groups between agreement with misconception statements and use of the specific form of reasoning we predicted the misconceptions to be rooted in. Importantly, these relations were seen throughout all student groups, in contrast to a previous study, pointing to the potential for these links to be firmly established well before undergraduate biology education. These results support previous evidence that intuitive patterns are deeply persistent, and thus may not be effectively addressed, even with advanced biology education. Addressing intuitive reasoning in biology and its links to misconceptions may provide a potentially more effective means toward improving evolution understanding in students.

\section{ACKNOWLEDGMENTS}

Many thanks to the monitoring editor, anonymous reviewers, and all SEPAL lab members for constructive comments and feedback that improved this article. We are also grateful to all of the supporting faculty and student participants. This research was supported by National Science Foundation CAREER Award 0954127 to K.D.T. and by National Science Foundation EHR Core Award 1535496 to J.D.C. and K.D.T.

\section{REFERENCES}

Alters, B. J., \& Nelson, C. E. (2002). Teaching evolution in higher education Evolution, 56, 1891-1901.

Arum, R., \& Roksa, J. (2011). Academically adrift: Limited learning on college campuses. Chicago: University of Chicago Press.

Atran, S., \& Medin, D. L. (2008). The native mind and the cultural construction of nature. Boston: MIT Press.

Belongia, E. A., Naimi, T. S., Gale, C. M., \& Besser, R. E. (2002). Antibiotic use and upper respiratory infections: A survey of knowledge, attitudes, and experience in Wisconsin and Minnesota. Preventive Medicine, 34, 346-352.

Brumby, M. N. (1984). Misconceptions about the concept of natural selection by medical biology students. Science Education, 68(4), 493-503.

Carey, S. (1985). Conceptual change in childhood. Cambridge, MA: MIT Press.

Cimpian, A., \& Markman, E. M. (2009). Information learned from generic language becomes central to children's biological concepts: Evidence from their open-ended explanations. Cognition, 113, 14-25.

Coley, J. D. (2000). On the importance of comparative research: The case of folkbiology. Child Development, 71(1), 82-90.

Coley, J. D., \& Tanner, K. D. (2012). Common origins of diverse misconceptions: Cognitive principles and the development of biology thinking CBE-Life Sciences Education, 11(3), 209-215.

Coley, J. D., \& Tanner, K. D. (2015). Relations between intuitive biological thinking and biological misconceptions in biology majors and nonmajors. CBE-Life Sciences Education, 14, ar8.

Crowther, G. J., \& Price, R. M. (2014). Re: Misconceptions are "So yesterday!" CBE-Life Sciences Education, 13(1), 3-5.

Eng, J. V., Marcus, R., Hadler, J. L., Imhoff, B., Vugia, D. J., Cieslak, P. R., ... Besser, R. E. (2003). Consumer attitudes and use of antibiotics. Emerging Infectious Diseases, 9(9), 1128-1135.

Evans, E. M. (2008). Conceptual change and evolutionary biology: A developmental analysis. In Vosniadou, S. (Ed.), International handbook of research on conceptual change (pp. 263-294). New York: Routledge.

Evans, E. M. (2017). Bridging the gap: From intuitive to scientific reasoning The case of evolution. In Rutten, K., Blancke, S., \& Soetaert, R. (Eds.), Perspectives on science and culture. West Lafayette, IN: Purdue University Press (in press).

Evans, E. M., Rosengren, K., Lane, J. D., \& Price, K. S. (2012). Encountering counterintuitive ideas: Constructing a developmental learning progression for biological evolution. In Rosengren, K. R., Brem, S., Evans, E. M., \& Sinatra, G. (Eds.), Evolution challenges: Integrating research and practice in teaching and learning about evolution (pp. 174-199). New York: Oxford University Press.

Gelman, S. A., \& Rhodes, M. (2012). "Two-thousand years of stasis": How psychological essentialism impedes evolutionary understanding. In Rosengren, K. R., Brem, S., Evans, E. M. \& Sinatra, G. (Eds.), Evolution challenges: Integrating research and practice in teaching and learning about evolution (pp. 3-21). New York: Oxford University Press.

Gelman, S. A., \& Ware, E. A. (2012). Conceptual development: The case for essentialism. In Margolis, E., Samuels, R. \& Stich, S. P. (Eds.), Oxford handbook of philosophy of cognitive science (pp. 454-479). New York: Oxford University Press.

Gregory, T. (2009). Understanding natural selection: Essential concepts and common misconceptions. 2, 156-175.

Gregory, T., \& Ellis, C. (2007). Conceptions of evolution among science graduate students. BioScience, 59(9), 792-799.

Huttner, B., Goossens, H., Verheij, T., \& Harbarth, S. (2010). Characteristics and outcomes of public campaigns aimed at improving the use of antibiotics in outpatients in high-income countries. Lancet Infectious Diseases, 10(1), 17-31

Inagaki, K., \& Hatano, G. (2002). Young children's naive thinking about the biological world. New York: Psychology Press.

Inagaki, K., \& Hatano, G. (2006). Young children's conception of the biological world. Current Directions in Psychological Science, 15, 4177-4181.

Kampourakis, K., \& Zogza, V. (2008). Students' intuitive explanations of the causes of homologies and adaptations. Science and Education, 17, 27-47.

Kelemen, D. (2011). Teleological minds: How natural intuitions about agency and purpose influence learning about evolution. In Rosengren, K. 


\section{Richard et al.}

\& Evans, E. M. (Eds.), Evolution challenges: Integrating research and practice in teaching and learning about evolution (pp. 66-92). Oxford: Oxford University Press.

Kelemen, D., \& Rosset, E. (2009). The human function compunction: Teleological explanation in adults. Cognition, 111, 138-143.

Maskiewicz, A. C., \& Lineback, J. E. (2013). Misconceptions are "So yesterday!" CBE-Life Sciences Education, 12(3), 352-356.

McNulty, C. A. M., Boyle, P., Nichols, T., Clappison, P., \& Davey, P. (2007). The public's attitudes to and compliance with antibiotics. Journal of Antimicrobial Chemotherapy, 60(Suppl. 1), i63-i68.

Nehm, R. H., Poole, T. M., Lyford, M. E., Hoskins, S. G., Carruth, L., Ewers, B. E., \& Colberg, P. J. S. (2008). Does the segregation of evolution in biology textbooks and introductory courses reinforce students' faulty mental models of biology and evolution? Evolution: Education and Outreach, 2, 527532

Nehm, R. H., Rector, M. A., \& Ha, M. (2010). "Force-talk" in evolutionary explanation: Metaphors and misconceptions. Evolution: Education and Outreach, 3, 605-613.

Nehm, R. H., \& Ridgeway, J. (2011). What do experts and novices "see" in evolutionary problems? Evolution: Education and Outreach, 4(4), 666-679.

Sealey, A., \& Oakley, L. (2014). Why did the Canada goose cross the sea? Accounting for the behaviour of wildlife in the documentary series Life. International Journal of Applied Linguistics, 24(1), 19-37.
Sepulveda, C., Mortimer, E. F., \& El-Hani, C. N. (2014). Conceptual profile of adaptation: A tool to investigate evolution learning in biology classrooms (163-200) (Conceptual Profiles). Dordrecht, Netherlands: Springer.

Shtulman, A. (2006). Qualitative differences between naïve and scientific theories of evolution. Cognitive Psychology, 52(2), 170-194.

Shtulman, A., \& Harrington, K. (2015). Tensions between science and intuition across the lifespan. Topics in Cognitive Science, 8, 118-137.

Shtulman, A., \& Schulz, L. (2008). The relation between essentialist beliefs and evolutionary reasoning. Cognitive Science, 32, 1049-1062.

Shtulman, A., \& Valcarcel, J. (2012). Scientific knowledge suppresses but does not supplant earlier intuitions. Cognition, 124, 209-215.

Speth, E. B., Shaw, N., Momsen, J., Reinagel, A., Le, P., Taqieddin, R., \& Long, T. (2014). Introductory biology students' conceptual models and explanations of the origin of variation. CBE-Life Sciences Education, 13, 529-539.

Tamir, P., \& Zohar, A. (1991). Anthropomorphism and teleology in reasoning about biological phenomena. Science Education, 75, 57-67.

Wester, C. W., Durairaj, L., Evans, A. T., Schwartz, D. N., Husain, S., \& Martinez, E. (2002). Antibiotic resistance: A survey of physician perceptions. Archives of Internal Medicine, 162, 2210-2216.

World Health Organization. (2015). Antibiotic resistance: Multi-country public awareness survey. Retrieved from World Health Organization website: http://apps.who.int/medicinedocs/documents/s22245en/s22245en.pdf 